\title{
An Exploratory Study on Benefit Evaluation of Cultural Creative Enterprises
}

\author{
Qin Lishuan, Guo Yanli*
}

Business College, Beijing Union University, Beijing, China

Email address:

lishuan.qin@buu.edu.cn (Qin Lishuan),yanli.guo@buu.edu.cn (Guo Yanli)

${ }^{*}$ Corresponding author

\section{To cite this article:}

Qin Lishuan, Guo Yanli. An Exploratory Study on Benefit Evaluation of Cultural Creative Enterprises. International Journal of Economics, Finance and Management Sciences. Vol. 8, No. 6, 2020, pp. 214-218. doi: 10.11648/j.ijefm.20200806.11

Received: September 1, 2020; Accepted: October 26, 2020; Published: November 4, 2020

\begin{abstract}
As China's political and cultural center, science and technology innovation center, Beijing has always been at the forefront of cultural and creative industries. In recent years, thanks to policies such as mass entrepreneurship and internet plus, Beijing's cultural and creative industries have ushered into a new era. The purpose of this study was to create a benefit evaluation system for the cultural and creative industries that are of great importance to society and government. This study used Delphi method to build a preliminary evaluation model, conducted questionnaires, conducted and interpreted factor analysis, and drew a conclusion on the factors that comprise of a comprehensive benefit evaluation system. The study shows that evaluation index system of cultural and creative enterprises mainly includes two parts: economic benefit index and social benefit index. For economic benefit index, the evaluation involves income level, brand value, cost input and economic drive effect. While for social benefit index, besides the usual tax contribution and employment contribution, it should also include indicators reflecting such characteristics of cultural and creative industries as brand demonstration effect, social morality drive effect, education effect and social capital. Hence, the benefits of the cultural and creative industries are demonstrated not only in generating more value for the region's economy but also in creating social value.
\end{abstract}

Keywords: Culture and Creativity, Enterprise Benefit, Evaluation Index, Exploratory Study

\section{Introduction}

As China invests heavily in cultural and creative industries, they are becoming of paramount importance to the development of both the economy and the society The cultural and creative industries in Beijing are picking up the pace of improving quality and efficiency, continuously optimizing geographic layout, activating market players, expanding and guiding cultural consumption, and making encouraging progress in culture propaganda. Industry clusters have helped key play a leading role in future development [1]. According to data from Beijing Municipal Bureau of Statistics, in the first half of 2017, the cultural and creative industries in Beijing have increased CNY 173.47 billion in value, a year-on-year increase of $13 \%$, accounting for $14.0 \%$ of the region's GDP. Revenue of industrial enterprises above designated size reached CNY 690.27 billion, growing by $8.6 \%$ year on year. Profit totals CNY 34.98 billion, a year-on-year increase of $30.6 \%$ [2]. These have enabled Beijing to not only adjust its economic structure, but also improve its urban functions.

In recent years, Beijing's cultural and creative industries accounted for the largest proportion of the GDP in all provinces, autonomous regions and municipalities nationwide, and the development momentum is very strong. However, to ensure the sustainable development of the industry, the first priority is to clarify its connotation and correctly position its function. It's worth noting that the cultural-creative industries have both merchandise properties and cultural properties, creating social benefits while bringing out economic benefits $[3,4]$. Without economic benefits and profits, the cultural-creative companies cannot form an industry. But if attention is only paid to economic benefits and its profitability, it will deviate from the original intention and goal. The demonstration effect of culture lead is not merely a numerical indicator of the economic benefits, but more important is the social benefits. Thus the purpose of this research is to construct a scientific and reasonable comprehensive benefit 
evaluation index system based on the full analysis of the economic and social benefits of cultural and creative industries, and provide theoretical support for the comprehensive benefit evaluation of cultural and creative industries in the future.

\section{Construction of Benefit Evaluation Index System for Cultural-creative Companies}

\subsection{Connotations of Cultural-creative Companies}

Definitions concerning the cultural and creative industries vary from country to country, region to region. The cultural and creative industry is named as "creative industry" in countries like Germany, Finland, Japan and Korea, whereas "copyright industry" in America, and "cultural and recreational industry" in Spain [5]. As different conceptual expressions arise among different institutions and individual scholars in recent years, controversies still exist related to the relationship between creative industries and cultural industries. Here are main viewpoints: in Beijing, the cultural and creative industry is defined as industry cluster, which has inherent connections, providing the public with cultural experience by taking composition, creation and innovation as basic means, cultural content and creative results as core value, realization and consumption of intellectual property rights as transaction characteristics. In Shanghai, it is defined as an industry that causes an increase in value at the links of production and consumption through a series of creation activities, centered on knowledge- and intelligence-intensive elements such as innovative thoughts, skills and advanced technologies which can create wealth for society and provide wide employment opportunities, highlighting innovation, creativeness, wealth and employment. Hu Gang points out that the development of Shanghai's cultural and creative industries should be open and inclusive [6]. Xu Hanming and Zhou Zhen hold that cultural and creative industries emerge when the cultural industry reaches a new stage of development [7]. The cultural industry is created by fusing culture and economy, while the cultural and creative industries are a new stage of the fusion of culture and economy. Xing Hua argues that the cultural and creative industries are referred to as an industry that has the potential of improving employment and create wealth, by exercise of intellectual property rights and numerical technologies, centered on creativeness [8]. The cultural and creative industries, which integrate emerging industries like cultural industries and creative industries, is a concept being rich in connotation. According to the Classification Standard of Beijing Cultural Creative Industry in 2008, the cultural and creative industries were divided into nine classification standards for cultural and creative industries, which are listed as follows: culture and art; Press and Publishing; radio, film and TV; software, network and computer services; advertisement and exposition; artwork trading; design services, tour, recreation and entertainment; other auxiliary services etc.

To sum up, although the related expressions are different among individual scholars, countries and regions, they are inseparable from the points below. First, "creativeness" is emphasized, in other words, human creativity is the core factor of creative industry. The role of human aptitude, wisdom and emotion is valued as the source of cultural and creative industries. Second, "culturality" of the cultural industry is underscored, which means culture, art and their spirits are the inexhaustible power and source. Third, "technology" is stressed, namely, modern technology and new media technology, such as informatization, digitization and intelligentization are the key factors. In a word, cultural and creative industries are brought about by the fusion of culture with economy and technology, which is also an important way for culture production and reproduction in scale, and even more a primary means of improvement for cultural communication, influence and soft power.

\subsection{Benefit Evaluation Index for Cultural-creative Companies}

Achieving economic benefits is the basis and prerequisite for the survival of cultural creative companies. Economic benefits are measured by comparative relations between useful results and labor consumption, or the relations between economic incomes (hereinafter referred to as income) and costs. It can be seen in the definition of economic benefits that economic incomes $=\mathrm{f}$ (income, cost), that is, any expression that carries out comparison and association research on incomes and costs belong to economic benefit category. There are mainly two indication methods for its expression, i.e.

$$
\text { Pure (or Net) economic income }=\text { income }- \text { cost; }
$$

Economic efficiency $=$ income $/$ cost

For specific enterprise projects measured from the perspective of economic benefits, only when the income is higher than cost, it can be illustrated that there are development and progress in enterprise operations, otherwise, enterprises will be eventually stuck in trouble.

Therefore, with the combination of characteristics of cultural and creative industries, several indicators for measurement of cultural and creative industries are enumerated, i.e. income level, cost input, creative brand value, economic radiation and drive.

\subsection{Evaluation Index for Social Benefits of Cultural-creative Companies}

Cultural creative companies should notice that the core value of educating, leading and promoting comprehensive development of people through advanced cultural heritage should not be weakened merely for the sake of economic benefits, while offering a wide range of diversely leveled cultural products and cultural services [9]. Without support in spirituality and value, the product of the cultural creative companies will lose its identity and become a tree without root. 
In other words, cultural-creative companies must consider social benefits while striving for economic benefits.

Social benefits refer to the contribution the enterprise makes to the society, also known as external and indirect economic benefits [10].

Hence, the social benefit indicators of cultural creative companies are listed as follows: reasonable use of resources, payment of profits and taxes, provision of employment opportunities, demonstration effect of brands, provision of training and education opportunities, etc.

\subsection{Benefit Evaluation Index System for Cultural Creative Companies}

If cultural products and cultural services are unpopular on the market, economic values cannot be realized, and social benefits are out of the question [11]. Thus it requires cultural product and cultural service providers not only follow the related composition rules of spiritual and cultural products, but also abide by the operation rules of market economies, working hard to compose and produce works and products that embody multi-leveled spiritual and cultural requirements of the general public and mainstream values. That is to say, to accelerate sustainable and healthy development of cultural and creative enterprises, it is necessary to persevere in the integration of entertainment function and education function.

Therefore, this research develops a causal relationship model for the benefits and the function achievement of cultural and creative enterprises, as shown in Figure 1.

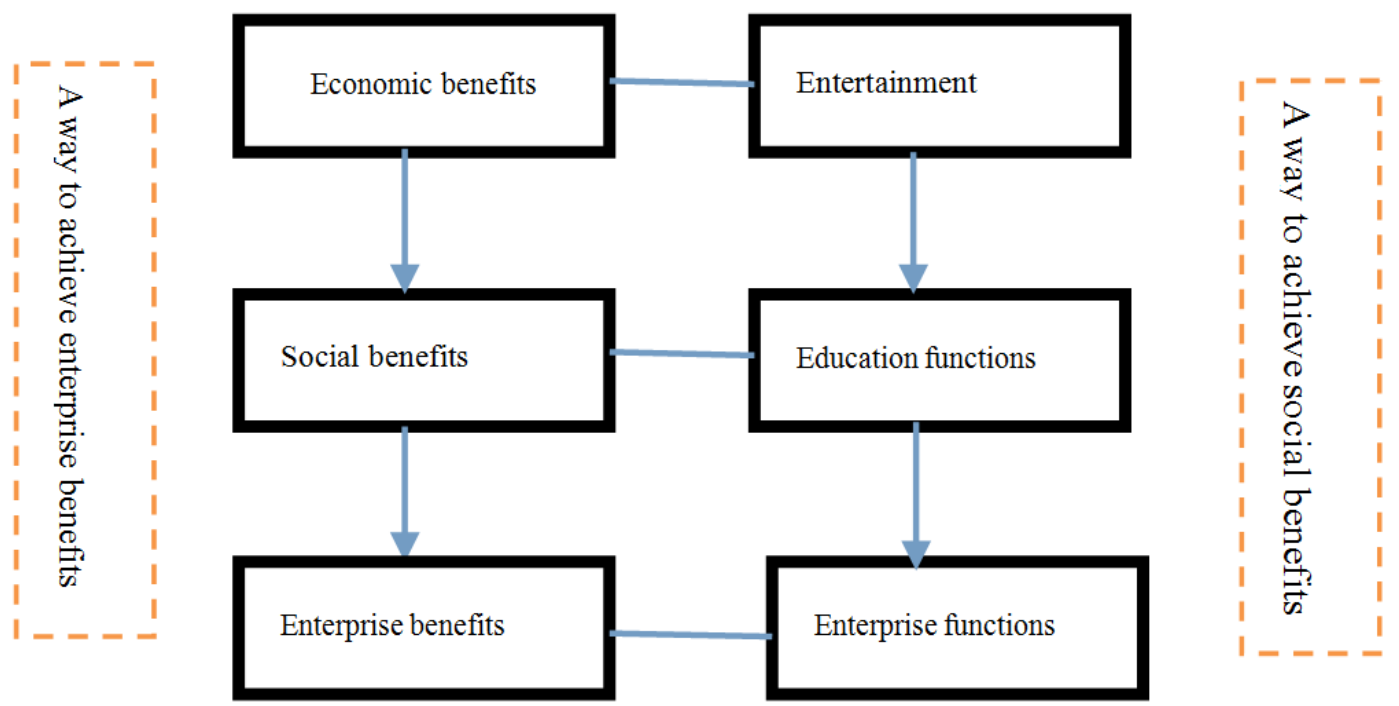

Figure 1. Causal relationship model for benefits and function achievement of cultural and creative enterprises.

By integrating the above mentioned evaluation indicators of economic benefit and social benefit, this study develops a benefit evaluation index system for cultural creative companies, as shown in Table 1.

Table 1. Benefit evaluation index system for cultural-creative companies.

\begin{tabular}{lll}
\hline Level 1 index & Level 2 index & Level 3 index \\
\hline & & Income level \\
& Cost input \\
& Creative brand value \\
Enterprise benefits & & Economic radiation and drive \\
& & Paying for profits and taxes \\
& & Providing employment opportunities \\
& Social benefit & Brand demonstrating effect \\
& & Providing training and education opportunities \\
\end{tabular}

\section{Case Analysis of Benefit Evaluation Index of Cultural Creative Companies in Beijing}

This study takes the cultural creative companies registered in Beijing as the study object and randomly extracts 190 enterprises as samples. The key factors considered are as follows.(1) The sample enterprises cover nine cultural and creative industries previously mentioned; (2) The samples include corporate decision-making staff, financial management staff, product developers and sales staff, etc.; (3) Multi-method approach is adopted in this research. In other words, questionnaire, interview and triangulation are all involved to achieve reliability.

\subsection{Delphi Survey}

For this study, Delphi method is used for main reference, and the steps of which are as follows: 
(1) According to the category of questions, 240 corporate management staff are selected, who are supposed to have conducted related research or have related experiences.

(2) Survey questions are distributed to each individual, and then he or she is requested to write down his or her own opinions separately.

(3) Survey opinions are formed. The survey scale is shown in Table 2, and the survey results are shown in Table 3.

Table 2. Benefit evaluation scale for cultural-creative companies.

\begin{tabular}{lllll}
\hline Index & Score value & Hard to say & Not very important & Very unimportant \\
\hline Benefit index & 1 & 2 & 3 & 4 \\
\hline
\end{tabular}

Table 3. Survey results of benefit evaluation index for cultural creative companies.

\begin{tabular}{llll}
\hline Benefit dimension & Economic benefit index & & \\
\hline Evaluation index & Income level & Value of creative brand & Cost input \\
\hline Importance evaluation score & 381 & 386 & 380 \\
\hline
\end{tabular}

Table 3. Continued.

\begin{tabular}{|c|c|c|c|c|c|c|c|}
\hline Benefit dimension & Social benefit & ndex & & & & & \\
\hline Evaluation index & $\begin{array}{l}\text { Tax } \\
\text { contribution }\end{array}$ & $\begin{array}{l}\text { Education } \\
\text { and training }\end{array}$ & $\begin{array}{l}\text { Brand demonstration } \\
\text { effect }\end{array}$ & $\begin{array}{l}\text { Social morality } \\
\text { drive }\end{array}$ & $\begin{array}{l}\text { Social capital } \\
\text { increment }\end{array}$ & $\begin{array}{l}\text { Employment } \\
\text { contribution }\end{array}$ & $\begin{array}{l}\text { Industry } \\
\text { influence }\end{array}$ \\
\hline $\begin{array}{l}\text { Importance } \\
\text { evaluation score }\end{array}$ & 528 & 467 & 404 & 426 & 481 & 483 & 427 \\
\hline
\end{tabular}

In evaluation of indicator importance provided by 240 subjects, the total score no more than $480(2 * 240)$ is defined as the important evaluation index. It can be observed from Table 3 that cost input, income level, value of creative brand, brand demonstration effect and social morality drive are ranked in order of importance. Hence, cultural creative enterprises should consider the previously mentioned factors while pursuing for their economic benefits, which is coincidentally consistent with reality.

\subsection{Factor Analysis}

To further justify the evaluation index system, a questionnaire is also designed. During the survey, subjects are invited to make performance evaluations on one project they are most familiar with. The results of factor analysis are as follows.

Table 4. KMO and Bartlett tests.

\begin{tabular}{|c|c|c|}
\hline Kaiser-Meyer-Olkin measure with adequate sampling & & .792 \\
\hline \multirow{3}{*}{ Bartlett ball test } & approximate chi-square & 567.238 \\
\hline & Df & 55 \\
\hline & Sig. & .000 \\
\hline
\end{tabular}

Table 5. Total variance explained.

\begin{tabular}{|c|c|c|c|c|c|c|c|c|c|}
\hline \multirow[b]{2}{*}{ Component } & \multicolumn{3}{|c|}{ Initial eigenvalues } & \multicolumn{3}{|c|}{ Extraction sums of Squared Loadings } & \multicolumn{3}{|c|}{ Rotation sum of squared loadings } \\
\hline & Total & $\begin{array}{l}\% \text { of } \\
\text { variance }\end{array}$ & $\begin{array}{l}\text { \% of } \\
\text { accumulation }\end{array}$ & Total & $\begin{array}{l}\% \text { of } \\
\text { variance }\end{array}$ & $\begin{array}{l}\text { \% of } \\
\text { accumulation }\end{array}$ & Total & $\begin{array}{l}\text { \% of } \\
\text { variance }\end{array}$ & $\begin{array}{l}\% \text { of } \\
\text { accumulation }\end{array}$ \\
\hline 1 & 3.456 & 31.421 & 31.421 & 3.456 & 31.421 & 31.421 & 2.347 & 21.332 & 21.332 \\
\hline 2 & 1.314 & 11.945 & 43.366 & 1.314 & 11.945 & 43.366 & 1.726 & 15.688 & 37.020 \\
\hline 3 & 1.204 & 10.948 & 54.314 & 1.204 & 10.948 & 54.314 & 1.721 & 15.646 & 52.666 \\
\hline 4 & 1.068 & 9.706 & 64.020 & 1.068 & 9.706 & 64.020 & 1.249 & 11.355 & 64.020 \\
\hline 5 & .772 & 7.020 & 71.040 & & & & & & \\
\hline 6 & .710 & 6.452 & 77.493 & & & & & & \\
\hline 7 & .642 & 5.840 & 83.333 & & & & & & \\
\hline 8 & .516 & 4.693 & 88.026 & & & & & & \\
\hline 9 & .470 & 4.277 & 92.303 & & & & & & \\
\hline 10 & .454 & 4.130 & 96.432 & & & & & & \\
\hline 11 & .392 & 3.568 & 100.000 & & & & & & \\
\hline
\end{tabular}

Extraction method: main component analysis

Table 6. Rotated component matrix ${ }^{a}$.

\begin{tabular}{lllll}
\hline & Component & & \\
\cline { 2 - 5 } & $\mathbf{1}$ & $\mathbf{2}$ & $\mathbf{3}$ & \\
\hline V52 income level & .271 & -.273 & .659 & $\mathbf{4}$ \\
V63 brand value & .143 & .408 & .637 & .083 \\
V65 cost input & .263 & .263 & .603 & -.012 \\
\hline
\end{tabular}




\begin{tabular}{lllll}
\hline & Component & & \\
\cline { 2 - 4 } & $\mathbf{1}$ & $\mathbf{2}$ & $\mathbf{3}$ & \\
\hline V73 economic drive effect & -.148 & .129 & .631 & .089 \\
V57 tax contribution & .124 & .789 & .079 & .528 \\
V58 employment contribution & .174 & .816 & .089 & .102 \\
V88 industry influence & .200 & .104 & .059 & .059 \\
V91 brand demonstration effect & .802 & .283 & .191 \\
V92 social morality drive & .713 & .063 & .100 & .0311 \\
V93 education effect & .788 & .108 & .070 \\
V94 social capital & .550 & & .090 \\
\hline
\end{tabular}

Extraction method: main component

Rotation method: a Kaiser standardized orthogonal rotation method

a. Rotation converged in 5 iterations

Through factor analysis, it is found that a total of 4 key components are extracted on condition that the eigenvalue is more than 1. Among the factors listed, the income level, brand value, cost input and economic drive effect are well clustered in one component, which is in agreement with the evaluation indicator: economic benefit indictor. The remaining 7 factors belong to 3 other main components respectively. To be specific, tax and employment contribution are aggregated as one component; brand demonstration effect, social morality driving effect, education \& training effect, and social capital increment are clustered as another; industrial influence alone is taken as the third one. Given the degree of aggregation of factors, it is possible to divide the social and economic benefits into three aspects, i.e. macroscopic social contribution (tax, employment etc.), mesoscopic social demonstration (brand demonstration effect, social morality, education and training, social capital) and microscopic industrial impact.

\section{Conclusions and Implications}

To sum up, the evaluation index system of cultural and creative enterprises mainly includes two parts: economic benefit index and social benefit index. For economic benefit index, the evaluation involves income level, brand value, cost input and economic drive effect. While for social benefit index, besides the usual tax contribution and employment contribution, it should also include indicators reflecting such characteristics of cultural and creative industries as brand demonstration effect, social morality drive effect, education effect, social capital, and so on. Also, market plays a fundamental role in the development of cultural creative companies. Without market, there are no cultural and creative enterprises. If cultural and creative products are not popular, economic benefits cannot be realized, and social benefits are out of the question. Hence, it requires product providers of cultural and creative industries to follow the creation rules in this field, at the same time to comply with the operation rules of the market economy.

\section{References}

[1] Yu Wentao. Creative industry agglomeration, regional innovation and productivity growth [D], 2014 (1): 6-8

[2] Notice of Beijing Municipal Statistics on "Beijing Cultural and Creative Industries Classification Standard" [EB/OL], 2017 (5)

[3] Ma Jun. The evolution of the development model of China's cultural and creative industries [J]. Academic Exchange, 2016, (06): 130-135.

[4] Jin Yuanpu. New forms, new trends and new problems of the current development of cultural and creative industries in my country [J]. Journal of Renmin University of China, 2016 (4): 98-105.

[5] Liu Ruxia. Research on Evaluation and Influencing Factors of Innovation Ability of China's Cultural Creative Enterprises [D]. 2018 (5): 9-10

[6] Hu Gang. Creative development of urban industrial heritage [J]. Shanghai Academy of Social Sciences, 2016 (5).

[7] Xu Hanming, Zhou Zhen. Research on the evaluation index system of creative industry parks based on the analysis of factors affecting environmental validity $[\mathrm{J}]$. China Soft Science, 2017 (03): 164-177.

[8] Xing Hua. Analysis on the integration of cultural and creative industry value chain and its development path [J]. Economic Management. 2009 (02) 37-41.

[9] Clare K. The essential role of place within the creative industries: Boundaries, networks and play [J]. Cities, 2013, 34: $52-57$

[10] Cai Dahai, Yang Yongzhong. Statistic Framework of Social Benefit of Cultural Industry: Comparison and Thinking [J]. Development Research, 2013 (12).

[11] Cong Haibin. The Research on Establishing Evaluation Index System of Cultural Creative Enterprise Core Competitiveness [J]. ENTERPRISE VITALITY, 2011 (01), 174-188. 